\title{
Why a Uniform Basic Income Offends Justice
}

\author{
JULIA MASKIVKER \\ Rollins College
}

\begin{abstract}
This article explains why the traditional defense of the basic income policy is flawed in its assumptions about uniform allocations. This paper argues that treating everybody identically by way of a uniform grant is ultimately in tension with the egalitarian rationale behind the basic income. Philippe Van Parijs, the champion defender of the policy proposal, has fervently argued that unconditional receipt of a universal grant will render society more just by way of the egalitarian distribution of 'real freedom' that the policy would elicit. Although Van Parijs is right in supposing that basic income will enhance real freedom, his theoretical apparatus is not prepared to address questions of differences in the level of opportunity already enjoyed by the beneficiaries of the policy. This failure poses a problem for normative reasoning, namely, that morally relevant differences among individuals are ignored. This paper concentrates on the implications of this oversight and provides an equality metric that is better equipped to recognize disparity and its moral implications.
\end{abstract}

Keywords: basic income, justice, moral agency, equality, real freedom

JEL Classification: D31, E64, H24

\section{BASIC INCOME AND DIFFERENCE}

The basic income proposal has gained much traction during the last five years as a possible mechanism to fight poverty in advanced economies which are plagued by recession. In a short period of time, it has become the object of serious consideration in several countries of Europe. In the United States-a country that has been traditionally averse to generous and universal welfare policy-the idea of basic income has received heightened attention in the media; many have discussed its potential to cope with a changing job market due to the job market's increasing

AUTHOR's NoTE: The author would like to thank Bob Goodin, Jon Elster, Karl Wiederquist, two anonymous referees, and the editors of this journal and volume, Huub Brouwer and Thomas Mulligan, for insightful comments on earlier drafts of the paper. 
flexibility (Surowiecki 2016). ${ }^{1}$ The appeal of a basic income has also reached parts of the Global South. For instance, in Latin America, the initiative is at the center of a social movement to combat poverty in countries such as Brazil and Argentina (Valente 2009). Such considerations suggest that basic income is more than academic conjecture: its growing presence in policy discussions around the globe indicates that it is a proposal with great opportunity.

Over the last three decades, much has been written in the justice literature about the merits of a basic income. Basic income is a guaranteed minimum income conceived of as the basis of a social security system, or as a complement to it (depending on how high its value is). Its proponents argue that the grant should be given to people unconditionally-that is, without an obligation to work-regardless of existing wealth and income. According to this perspective, every citizen is entitled to a basic income by right of birth (see Van Parijs 1995, as a paradigm case).

Basic income is not a single policy but a set of related policies based on the shared idea of a periodic (or one time) cash payment delivered to all on an unconditional basis (Van Parijs 1995; Atkinson 1996; Przeworski 1986). ${ }^{2}$ The basic goal behind this family of proposals is to guarantee (at least) a minimum income floor for all citizens and, by implication, to enlarge their capacity to choose among different life and employment plans. However, not all proposals are designed in the same way or support the same level of income given to citizens. Some authors defend a basic income proposal that sets its value as high as is economically possible to sustain (Van Parijs 1995; Wright 2003). ${ }^{3}$ This approach is usually consistent with the argument that most other forms of social welfare would cease to be necessary if this level of funding

\footnotetext{
${ }^{1}$ Among other things, Surowiecki explains that a basic income would increase workers' bargaining power by providing an income cushion that can help them when deciding whether to reject lousy, precarious job offers.

${ }^{2}$ My arguments in this paper, thus, also apply to a Capital Grant. For elaboration of this policy, see Ackerman and Alstott (2004). The Capital Grant, or Capital Account, proposed by the authors consists of a one-time delivery of $\$ 80,000$ to each adult in society when they reach 18 years of age, funded by an annual wealth tax.

${ }^{3}$ For this approach, see, classically, Van Parijs (1995). This 'maximalist' approach, however, is not taken by Van Parijs in his latest work with Yannick Vanderborght (Van Parijs and Vanderborght 2017). Here, the authors argue for a moderate level of funding in so far as it is not realistically possible to expect otherwise-this applies even in the most prosperous capitalist economies of the world. Further, the authors also argue that a moderate basic income is not supposed to replace all kinds of welfare assistance already in place. See also Wright (2010) for an alternative minimalist approach to basic income.
} 
were attained; though, others defend a minimum floor (one that is sufficient to cover basic needs) that should be complemented with other welfare programs.

Before we proceed, a word of caution. A basic income should not be confused with a Negative Income Tax (NIT). Many interpret the merits of basic income to be equivalent with the NIT policy, though this is a false equivalence: a NIT policy is based on household income, viz. those who earn below a certain income amount. ${ }^{4}$ Basic income, by contrast, is individualistic and thus applies to all by birth or citizenship. Moreover, as argued by Van Parijs and Vanderborght (2017), the crucial difference between the NIT policy and basic income is that, at least in its preferred formulation by Friedman (1962), a NIT is funded via a linear tax rate for all income levels. This is to say, that all levels of income are taxed at the same rate (Van Parijs and Vanderborght 2017, 32-35). But, as I will explain later in this article, not all basic income proposals are funded by taxation.

Since it would take us too far afield to discuss the details of all the different formulations of the basic income policy, I will here concentrate on a general definition of basic income that should be sufficient to achieve consistency among different interpretations of basic income. The reader is asked to think of the main (shared) definitional aspects of the policy as including universality (everybody gets it) and unconditionality (the policy is non-means tested and without workrequirement). In this article, I will not argue whether basic income should replace other forms of welfare assistance in society-this is because I do not defend any particular view about what the value of the basic income provided to citizens should be (such a defense is not necessary for the purposes of my argument). However, it will become clear that the higher the value of a basic income proposal is, the greater the discrepancy and unfairness will be: a generous level of income given to all universally will exacerbate the existing differences between those who do and those who do not need such income. Hence, the issue of what is the appropriate value for a basic income deserves a much more

\footnotetext{
${ }^{4}$ Initially popularized in the $20^{\text {th }}$ century by Milton Friedman in his Capitalism and Freedom (1962). The NIT is, basically, a system by which people earning below a certain amount receive supplemental pay from the government instead of paying taxes to the government.
} 
detailed economic analysis that can be provided here. ${ }^{5}$ Now, we are ready to explain my main claim in this article.

Contingent on the value of the grant, a basic income can give the individual freedom to withdraw from the sphere of economic production and gainful employment. The higher the value of basic income is, the less dependent the individual will be upon income which is derived from work. This is because the basic income granted will be provided irrespective of wealth and other indicators of socio-economic status. The higher the level of the grant, the freer from employment the individual will be. In other words, the generosity of the grant is inversely proportional to the individual's reliance on a wage or any other type of economic gain directly derived from her labor (such as gains derived from self-employment).

Opponents of unconditional and universal basic income oftentimes find the foregoing conclusion unpalatable because of its alleged unfairness. They point to the intuition that it is unjust that some people work to finance the freedom of others; call this the free-rider objection. The free-rider objection claims that living off other people's labor, labor which supports basic income via taxation, is objectionable because it entails taking unfair advantage of the industrious members of society (see Elster 1986; White 1997). On this view, those who do not prefer to work should not receive preferential treatment at the expense of those who do.

In this paper, I focus on a second, vastly underexplored objection against a basic income, which goes beyond the free-rider problem. The second objection to basic income is the idea that it is unjust that scarce resources be devoted to finance the (relative) freedom from work of unequally disadvantaged individuals in society. I call this the relevant differences objection. This objection points to the fact that in actual societies, not all individuals are subject to the same constraints, such as those imposed by the necessity to work for a living. Some people, for instance, are born and live in propitious circumstances that render the need to seek employment less demanding than for other individuals. From this fact, an important normative implication follows: society's provision of resources to reduce the constraints imposed by economic necessity should be sensitive to those differentials. This article explains why the traditional defense of the basic income is flawed in its

\footnotetext{
${ }^{5}$ Additionally, it may not evoke the same solution in all countries for obvious reasons related to the affluence and health of the world's different economies.
} 
assumptions about uniformity in the distribution of the grant money. The paper develops the argument that treating everybody identically is ultimately in tension with the egalitarian rationale behind the policy. Because of this tension, I propose to modify the rationale for and implementation of the policy. I argue that if we truly care about equality and real freedom, as Van Parijs does in his arguments for basic income throughout his oeuvre, we should prefer to establish a gradated income grant, not a uniform basic income that is identical for all regardless of individual circumstances.

According to the traditional defence of basic income, the unconditional grant should be available for absolutely everybody in society irrespective of any situational differences among individuals. Situational differences are disparities that stem from the individual's life-context, such as income, educational level, family environment, work opportunities offered by the community, and so forth. According to defenders of the basic income proposal, the income grant is founded on a citizenship right to economic support, and this right is blind to any disparities in the condition of recipients. It is based on the ideal of unqualified entitlement. ${ }^{6}$

This blindness to difference is justified by considerations of distributive equality. Philippe Van Parijs, the champion defender of basic income, has consistently argued that unconditional receipt of a uniform grant will render society more just by way of the egalitarian distribution of real freedom that the policy would elicit. Real freedom, according to Van Parijs, is the effective capacity to do "what one might want to do" (1995, 21). According to him, an unconditional grant provided to everybody equally will enhance people's power to engage in projects they like, or might like, to pursue in the future. It will enlarge their range of meaningful options in a manner that negative freedomunderstood as mere absence of interference-is not capable of doing. The reason why real freedom is distinguished from freedom as absence of interference is that real freedom requires more than absence of

\footnotetext{
${ }^{6}$ Participation income proposals are also universal in this sense. The participation income policy demands work in return for assistance but it applies to everybody regardless of social position. A participation income is a basic income that is universal (non-means-tested) but conditional. It differs from an unconditional basic income in that citizens must contribute something in return for the grant. This contribution typically consists of community work. Like basic income, however, the participation income is not variable. Everybody is entitled to it provided they commit themselves to 'giving back' to society in some discernible way. For a defence of participation income, see Atkinson (1996).
} 
humanly and legally imposed obstacles to action. It requires material resources and opportunities that enable the individual to stick by her preferences allowing her to perform actions that naturally follow from those preferences. The notion of real freedom as initially proposed by Van Parijs in his seminal book (1995) is not analytically complicated. One could understand it as personal autonomy in that it signifies the effective capacity to choose plans of life that may otherwise be formally available to us but are too expensive or not feasible to carry out. The literature refers to this capacity as positive freedom. In discussions around distributive justice, it signifies the presence of material resources and opportunities that enable the individual to go through with her choices. For example, one could be formally free to go to university because there are no laws prohibiting it, but the cost of a college education may be so high that most people may not be able to afford it in practice, rendering them less autonomous and free than the wealthy few who can. In the sense described in the basic income literature, real freedom is, more than anything, freedom from economic hardship and freedom to possess a certain level of income that would permit the individual to escape circumstances that are predicated on a lack of opportunity. One important reason why basic income confers real freedom by enlarging opportunity is that it gives the recipient the power to say no (see Widerquist 2006). Its purpose is not just to assuage poverty and misery, but to change the balance of power relations in society. A basic income would give individuals the power to decline precarious but necessary-to-survive job offers that deepen the cycle of poverty and stigma for those who have to take them in the absence of a better option. Thus, basic income is a source of real freedom because it provides individuals the chance to stand up against exploitation, which mostly affects the economically disadvantaged. ${ }^{7}$ A life without exploitation is certainly more free in the sense that Van Parijs describes when he talks about real freedom. But Van Parijs does not only worry about the danger of exploitation that a basic income would help combat: real freedom necessarily opposes exploitation, but it also entails the positive presence of opportunities to do things in life without being

\footnotetext{
${ }^{7}$ Additionally, and in a similar vein, the basic income avoids the so-called poverty trap that many welfare programs that require work to be dispensed create. Many times, recipients of assistance will refrain from taking precarious work because the pay will be so bad [insufficient?] that the assistance program is preferable; and if they take the job they will lose the latter. This dynamic traps them into a cycle of poverty because they cannot leave welfare easily on pain of much economic cost.
} 
judged or restrained for wanting to do them. Having real freedom entails that the individual is the sole arbiter of what is a valuable pursuit for them; and that the government remains neutral on the value of different life plans. The idea of real freedom in Van Parijs' work consists of (i) non-exploitation, (ii) availability of resources necessary to carry out plans, and (iii) governmental neutrality on the issue of what constitutes a good life.

However, although Van Parijs is right in supposing that basic income will enhance real freedom as described above, his theoretical apparatus is not prepared to address the 'relevant differences objection' that I described before. In other words, his work fails to address questions of difference in social advantage already enjoyed by the beneficiaries of the policy. This failure poses a problem for normative reasoning, namely, that morally relevant differences among individuals are ignored. I concentrate on the implications of this oversight and suggest an approach that is better equipped to recognize disparity and its moral implications. What I call the 'agency approach' is better suited to taking notice of differences that warrant moral concern from a justice viewpoint. For this reason, reference to it is appropriate in the framework of a discussion about policy proposals that should be sensitive to people's situational differences.

There is scarce treatment of this issue in the basic income literature, although the general spirit of my objection against a uniform basic income evokes an existing objection against sufficientarianism as a criterion for distribution. ${ }^{8}$ Arguments in favor of basic income-viz. those which cite it as a source of real freedom and autonomy by

\footnotetext{
${ }^{8}$ See, for example, Casal (2007). Broadly speaking, sufficientarianism as a criterion for distribution proposes that we should worry about bringing everyone over a minimum stipulated threshold of income but that differences in resources among people above that threshold do not matter morally or in terms of justice. The idea is that inequality of resources is not morally salient if everybody has sufficient resources to survive decently (what this means is subject to stipulation and I cannot go over the issue here). Casal presents a refutation of this claim and seeks to argue that inequality should matter to us. Her argument is complex and nuanced, but one could say that she proposes to highlight the appeal of prioritarianism, whereby the moral value of benefiting an individual decreases as she becomes better off (on an absolute or a relative scale depending on the stripe of prioritarianism in question). My arguments for a gradated basic income, in this paper, are consistent with Casal's normative assumptions against sufficientarianism and in favor of equality and prioritarianism. It would not be incorrect to say that a uniform basic income for all is oblivious to differences in income/welfare that already exist among citizen-recipients. Because of this, it is true that it would give the worse off an opportunity to surpass the threshold necessary for a decently good life but it would also leave those existing inequalities untouched or even accentuated.
} 
solidifying a right to say no and rebalancing relations of power in society-do not address the problem that this paper focuses on, which is that the uniform basic income ignores important moral differences in effective opportunity that would-be-recipients already enjoy. Some analyses of basic income do touch on differing levels of cash dispensation among citizens depending on their age and their geographic location (Van Parijs and Vanderborght 2017, 9). However, these differences are not justified on disparities of pre-existing effective capacity to act, but on more mundane considerations. There is no argument to address why considerations of justice and desert justify these distinctions (other than the idea that children are generally taken care of by parents, and some areas of the country are terribly more expensive than others to live in). This absence of analysis is not trivial. As logically valid as the existing arguments for a basic income are, it remains true that the notion of identical dispensation (uniformity) would seem to entail the assumption that, in the absence of a basic income at all, everybody's real freedom is affected in a way that we should lament. But this is obviously not the case as people's effective capacity to do things in life (and pay for them) varies according to family situation, personal background, inherited advantage, and other variables beyond their control.

The article has the following structure: Part Two challenges Van Parijs's conceptualization of equality. In that section, I argue that Van Parijs's uniformist account of equality is deficient because it is oblivious to relevant differences in individual situations. Van Parijs relies on a conception of distributive equality that ignores the importance of giving all individuals' interests equal consideration. The principle of equal consideration of interests is a cornerstone of egalitarian thought and Van Parijs does not offer any valid justification for (implicitly) overlooking it. In part Three, I claim that when it comes to basic income, a focus on pre-existing economic advantage is more appropriate than uniformity because it provides a clearer indication of whether people are morally responsible for their own predicaments, and if so, how. The argument is that, under normal circumstances, the least advantaged members of society have a moral claim to differentiated attention in the face of society's failure to provide them with the resources necessary to exercise moral responsibility. I refer to the capacity to exercise moral responsibility for life choices as 'moral agency'. It presupposes the opportunity to choose freely uninhibited by social contingencies, as far 
as that is humanly and reasonably possible (my view does not assume that unencumbered choice is ever plausible). Part Four deals with the policy implications of the approach to distributive equality that I propose. Part Five concludes.

\section{UNIFORMITY AND JUSTICE}

A uniform basic income is in tension with well-entrenched, commonsense moral views about justice. The assumption that uniformity is consonant with justice presupposes that situational differences do not matter for justice. But this assumption is at odds with some of our most basic egalitarian intuitions. Individuals living in conditions under which some of their fundamental interests are comparatively more difficult to fulfill due to disadvantage need greater help vis-à-vis those whose interests are already fulfilled, or whose backgrounds render fulfillment relatively cheap or easy. A fundamental interest in hydration, for example, is relatively cheaper to fulfill, ceteris paribus, for someone living by a non-polluted river than for someone living in a desert. ${ }^{9} \mathrm{~A}$ basic interest in decent housing, to take another example, is more likely to be fulfilled in the case of individuals born to relatively well-off families than it is for individuals born and raised in urban slums. A human interest in enjoying income security, lastly, would be easier to fulfill for the person living in an area of vibrant economic activity and innovation than it would be for a person stuck in a depressed, jobsscarce region.

\footnotetext{
${ }^{9}$ More attention is needed perhaps to the extent to which these factors are under the person's control. In many cases, a person does not have to live by a polluted river. Such cases raise two issues: Why should society have to pay you for choosing to live in a tougher environment? And does making such payments not pose problems of moral hazard? These observations, although valid, do not forcefully apply to the cases I have in mind and which motivate my focus on disparity in advantage. I assume that we will want to avoid on any rational grounds the disadvantages attached to places of residence. Thus, nobody in their right mind would choose to live by a polluted river if they could do otherwise. Usually, people residing in disadvantaged natural and social environments have been born there, or are stuck there for lack of social mobility or better employment prospects. Of course, not all cases are of this sort and many times people choose a low-quality residence environment in exchange for high pay or other benefits. These cases should be considered in a different light in that one could reasonably say that they involve much higher degrees of voluntariness. It is for these voluntary cases that one should fear moral hazard. But this is not a danger for my position since, as will be argued below, the indexes of advantage that I use will be income and wealth. This means that in trade-off cases such as the one of the high-earner who lives by a polluted river, her choice will not make her disadvantaged in the eyes of the policy-maker because she will be commanding a higher income than she otherwise would.
} 
In his work, Van Parijs does not seem to be concerned with how a uniform basic income would deal with the foregoing disparities in capabilities and individual situations. On the contrary, he lays special stress on the idea that an adequate conception of distributive justice would not compensate agents for welfare deficits arising from having expensive tastes (nor tax them for welfare surpluses due to cheap preferences) (see Van Parijs, 1991). In this sense, it is clear that his approach to justice is non-welfarist. A non-welfarist approach to justice naturally rejects the idea that disparities in levels of welfare and preference satisfaction deserve the attention of justice (Dworkin 1981b). Rather, the non-welfarist approach focuses on more objective standards of equality such as resources or opportunities. ${ }^{10}$ On the resourcist account, resources, such as money, and opportunities, such as access to jobs and other competitive positions in society, constitute a more reliable metric for equality because they are not subject to whims and mere subjective desires. For example, giving room to welfare considerations when making decisions about the just way to distribute resources in society may mean that those with unnecessarily expensive tastes may end up receiving more resources than others due to their peculiar preferences. Nobody needs an Aston Martin to enjoy a decent standard of living but some individuals may sincerely feel that the possession of a luxurious automobile is strictly necessary to that end. Even though expensive tastes can derive from real, verifiable human needs - as is the case of the person who gets violently sick if he ingests tap water, and needs mineral water instead-it is generally safe to assume that objective metrics of equality like resources or opportunities protect us against the tyranny of expensive tastes. The non-welfarist position, despite differences among approaches, entails the fundamental rejection of the idea that people cannot be held responsible for their preferences or tastes. In this sense, Van Parijs' views are not unconventional or unwarranted. Van Parijs is not concerned with preference satisfaction because he holds individuals responsible for their preferences. However, Van Parijs would justifiably tell us that his conception of justice does not assign responsibility for preferences formed under certain conditions of limited freedom, such as coercion, force, and informational insufficiencies. But, when freedom of choice is taken as given, he assumes that the individual is able to control what ${ }^{10}$ For a full-fledged and classical defense of the resourcist approach, but also an
explanation of the welfarist account, see Dworkin (1981a, 1981b). 
she prefers, and therefore, that the state has no business compensating her or actively facilitating the fulfillment of her expensive tastes. Furthermore, as mentioned before, a uniform basic income fulfills the goal of preserving state neutrality regarding the value of different plans of life because it does not treat any one choice as more or less worthy of support than another. In the face of these two assumptions, namely, that people are normally responsible for their tastes and that no way of life is better than another, a uniform distribution of resources is the most natural implication. The logic underwriting the uniform grant is that, if we wish to avoid falling prey to welfarism and to perfectionism, a uniform distribution of resources is the most appropriate alternative when it comes to choosing a metric for equality. Van Parijs suggests that, to avoid putting preference satisfaction at the center of a theory of justice, and to avoid making assumptions about which life-plans are morally preferable overall, we must ignore disparity and make basic income the same for all.

However, a fear of welfarism and of perfectionism ought not to overshadow a commitment to equality. There is a way out. The alternative is exemplified by an emphasis on moral agency understood as the freedom to make choices that are unencumbered by initial social disadvantage. The term 'moral agency' entails reference to moral responsibility. When we are relatively unburdened by oppressive social circumstances, we are relatively more free to act, and therefore better equipped to claim moral responsibility for what we do or do not choose to do. People are not all equally responsible for the results of their decisions because they experience different degrees of constraint when making those decisions. That constraining circumstances imperil moral responsibility for many of the choices we make in life is a common premise in philosophical discussions about justice. The less burdened by initial economic disadvantage a person is, the more truly responsible for her actions she can be said to be. ${ }^{11}$ To be free in this respect implies the possession of resources and opportunities that make our formal choices possible. In other words, being free entails not only being free to make choices (freedom from intrusion), but also being free to carry out the plans that logically follow from those choices because we have the substantive resources necessary to do so. In the absence of effective opportunity to carry out our plans, the force of circumstance becomes

\footnotetext{
${ }^{11}$ For a good survey of the moral responsibility literature, see Fischer (1999, 2008), Levy and McKenna (2009), and Campbell (2008).
} 
powerful because we are confined to choosing among a very limited number of options even if we are formally free to choose among a broader menu of alternatives.

For example, I am formally free to choose to attend an expensive private institution of higher learning; but even if I get admitted to it, I may not be truly free to carry out my plan to study there if I do not have the monetary resources or financial assistance that would enable me to take my preferred course of action. In line with this premise, I argue that if we care about justice and a fair distribution of real freedom, the allocation of resources necessary to implement a basic income must track existing differentials in initial (dis)advantage among would-be recipients of the income grant.

Neglecting to look at differences among individuals defeats the egalitarian purpose that animates the basic income policy. Recognizing difference does not necessarily imply enslaving society to the whims and expensive tastes of (some of) its members. People do not only differ in their preferences but they also differ in the conditions of advantage that they experience and are born into. This fact has important implications for justice. Personal circumstances play a role in determining how morally accountable a person is for the features that largely shape her life. The more control she has over those circumstances, the more morally responsible she can be thought to be for the shape that her fate takes.

To claim that a person is morally responsible for a certain action or situation is to claim that such an action or situation is attributable to her in the sense required for it to be a basis of moral appraisal. We appraise someone in this sense when we consider blaming them, or absolving them of blame, for a particular predicament they are immersed in (see Frankfurt 1969; Zimmerman 1987). Being capable of moral responsibility, in turn, implies freedom, for in the absence of freedom no evaluation of the person's blameworthiness can be made. In each case, facts about degrees of control, facts about the quality of options, and facts about the costs of alternatives affect the proper allocation of moral responsibility. The concept of agency gives us a standard to assess moral responsibility by looking at the individual's context of choice. It tells us that the capacity to claim moral responsibility for decisions and circumstances differs across people according to the nature of the options they face in life. All else being equal, the more advantageous her initial options, the more of a moral 
agent the individual can act as. To be morally responsible for the shape of one's life is to be in command of one's life, that is, to be able to choose and to realize those choices, rather than to have those choices, and actions, determined by circumstance..$^{12}$ Thus, assessment of moral responsibility is possible, to a large extent, the more genuine choice there is. Moral agency and real freedom are opposite sides of the same coin.

At this juncture, however, we may wonder how exactly my moral agency approach differs from the real freedom standard and, if so, what it adds to the normative analysis of basic income. The concept of moral agency adds to the concept of real freedom (they are not mutually exclusive) by bringing into the picture a concern with the past and its effects on moral responsibility for things we have (had) to endure or have (had) to enjoy. In other words, talk of moral agency means taking account how the past affects the present and may affect the future in a way that we cannot be blamed or praised for. This can either be because we are the victims of unchosen disadvantage or because we are the beneficiaries of fortune and wealth that we have not created. The concept of real freedom takes a picture of the present and does not place it in the overall framework that our life is; it only takes a snapshot of our current life. The concept of moral agency does a better job of drawing conclusions about the place that such a picture should occupy in the album that is our whole personal trajectory. In other words, the concept of moral agency allows us to investigate how, if at all, our present situation was affected (adversely or positively) by circumstances that would be reasonable to assume were outside of our control.

Perfect uniformity in the dispensation of a basic income, I argue, will positively affect real freedom for those who lack it, but it does nothing to respond to the different levels of that freedom that people already

\footnotetext{
${ }^{12}$ Circumstances are always going to influence our actions, in the sense that they determine what counts as the stakes of our actions. A relevant circumstance for whether I take the bus to university in the morning is the number of other people on that bus, something that I do not control. However, when I refer to 'circumstances' in this paper I have in mind a less trivial set of situations that, we can all agree, have a significant impact on people's life prospects. Poverty, and socio-economic background more generally, are examples of these types of situations. When John Rawls referred to "morally arbitrary" (Rawls 1971, 17) factors that can influence a person's life trajectory significantly, he surely had in mind something similar in nature to my description of a non-trivial circumstance. My idea, then, is not original in any sense of the term and it is a standard assumption in the equality literature of the last 40 years. Of course, many circumstances affect decisions and what happens to us, but not all of them do so with the same degree of relevance and impact.
} 
enjoy because it does not take into account differences in circumstance that are the source of, or an impediment to, real freedom.

Why are situational differences important when discussing how to implement the basic income in particular? They are important simply because many people's life options may be gravely truncated even after receipt of a basic income grant. If I live in an urban slum and my parents are poor and under-employed, there is reason to doubt that a grant will drastically modify my prospects. I will still be largely constrained by initial, adverse circumstances. In the presence of this constraint, the idea that I am morally responsible for the shape of my life is dubious. This is not to say that individual initiative is impossible. It is only to say that the person who is subject to constraints she did not choose, and which are relevantly burdensome, cannot be held responsible for her fate in the same way as someone who is largely free from undesirable, constraining social circumstances. ${ }^{13}$

On the other hand, the moral agency of many individuals may not be enhanced by the grant but for opposite reasons. If Bill Gates lives in a society where basic income is provided for all, the change in possibilities afforded by the grant is so minimal that it will not make a real difference in his life (unless he is taxed at such a high a rate that almost all his post-tax income evaporates). In this case, the uniform policy seems little more than a waste of valuable social resources. My contention is that when deciding how to allocate the resources associated with the basic income, implementation should be based on actual levels of socio-economic advantage. This focus, in turn, will allow us to evaluate how morally responsible for her overall situation a person is. In other words, it will allow us to see how much moral agency she can claim to have exercised with regard to circumstances that are beyond her control.

Questions of moral agency are crucial for determining the justness of people's claims to institutional attention. But Van Parijs' equality metric frustrates his intention to take individual responsibility into account in his political philosophy. With the intention of barring welfarism from the normative scene, Van Parijs is unwarrantedly kind towards people who have the means to live their lives without additional benefits; and he is too harsh with individuals who do not have access to

\footnotetext{
${ }^{13}$ The idea that people are always fully responsible for their own outcomes implies the 'Just World Syndrome'. This is the belief that whatever happens to people is just; the victims always bring about their fates. See Lerner (1980).
} 
a similar fortune through no fault of their own. The following example illustrates this point. ${ }^{14}$

Imagine you have two children. One of them, child A, is healthy and quite happy. The other, child $\mathrm{B}$, is afflicted with a seriously painful disability that requires him to consume more food than the first child. Under the assumption that the family's resources are scarce, it would be an inegalitarian decision to provide both children with the same amount of food. In this case, egalitarian intuitions compel us to not treat the two children identically. It is more urgent to benefit the handicapped child on account of his situation. ${ }^{15}$

The conception of moral equality at work in the above example can be contrasted with equality defined as identical treatment. If we accept that giving equal weight to people's moral claims is a crucial requirement for justice, it is clear that the disabled child's claim to a bearable life should be as important as the non-disabled child's claim. Insofar as Van Parijs fails to recognize relevant differences that separate individuals-such as differences in the enjoyment of basic social goods like income, security, health, and others-it makes sense to say that his concept of basic income is in tension with an ideal of equality that emphasizes equal consideration of interests. By supporting a uniform basic income, he seems to rely on a purely formal conception of equality whereby identical treatment is a sufficient and necessary condition of justice. ${ }^{16}$

However, there are reasons to argue that identical treatment is not always a reflection of justice. Van Parijs, it must be said, in no way argues that assistance to the disabled and the sick in society will be precluded by the basic income. His defense of the policy is compatible with a welfare state that will compensate the disabled, the sick, and the incapacitated (Van Parijs 1995, 77-85). Nevertheless, this precaution is insufficient to honor the ideal of equal consideration of interests. The reason why a welfare state tasked with helping the sick and the

\footnotetext{
${ }^{14}$ I draw from Thomas Nagel's example, as given in his Equality and Partiality (1991, chap. 10).

${ }^{15}$ It has been objected that a conception of equality based on this notion is really not egalitarian but prioritarian (see Parfit 1991). This objection seems to me ineffective, since it assumes that equality is only strict equality in distributive terms. However, equality could be understood broadly, as a doctrine that requires that all moral claims be properly attended to, which may require prioritarianism.

${ }^{16}$ At least when it comes to implementing the basic income policy strictly. This does not mean that Van Parijs is opposed to complementing the basic income with other forms of welfare assistance.
} 
incapacitated is insufficient in the eyes of justice is that morally relevant differences also exist among able-bodied and healthy individuals; this was demonstrated by the examples of the urban slum dweller and the residents of economically depressed areas. In other words, morally relevant disparities of condition in society also spring from initial social and economic disadvantage, poor access to primary goods necessary for a decent living standard, and reduced opportunity to advance in life despite reasonable effort and initiative; disability is not the only cause of morally relevant differences. Thus, Van Parijs' defense of welfare programs that coexist with the basic income, and whose purpose is to meet the needs of the incapacitated, is not satisfactory as a solution to the existence of morally relevant disparities among citizens in complex societies like ours.

The most obvious response to my objection that a uniform basic income offends justice will likely be that the funding method for the basic income renders that objection moot. In other words, if the basic income is to be financed mostly via income taxes, then that means the rich who also receive it will experience no positive gain as the effects will be cancelled out by the taxes that they will have to pay to support it in the first place. On the contrary, the wealthy will experience a net loss because the income paid to the state in the form of taxes will probably be higher than the basic income grant. My response to this line of argument is as follows.

First, it is not certain that the only way to fund a basic income is via income taxes. ${ }^{17}$ The literature has dealt with various other sources of funding for the policy, which, if put in practice, would not result in the better-off experiencing net losses (but net gains). For example, the basic income could be funded by using public ownership of natural resources. This idea comes in three versions (Van Parijs and Vanderborght 2017, 149). First, the state could rent out a valuable resource it owns and use the funds to sustain a basic income. ${ }^{18}$ A second way of funding a basic income out of publicly owned assets would be to use the revenues from selling a non-renewable natural resource such as oil or a precious metal, among many others. A third way of funding a basic income via a stateowned resource is to use the sale of that resource to create a permanent

\footnotetext{
${ }^{17}$ This fact means, logically, that if the taxes paid by those who do not need a basic income end up offsetting the grant, it would not be an injustice for them to receive the grant. However, it may be a gross act of inefficiency on the part of government.

${ }_{18}$ This was Thomas Paine's (1791) proposal for funding a basic endowment and a pension for the young and old, respectively.
} 
sovereign fund - a financial instrument that would trade in the market for shares-and distribute dividends to citizens. The real-life example of this option is the famous Alaska Permanent Fund. ${ }^{19}$ Basic income could also be conceivably funded via carbon taxes on corporations, but this form of funding would not necessarily affect salaried wealthy individuals such as CEOs, and high-earning professionals such as plastic surgeons, corporate lawyers, or Wall Street traders. In sum, income taxation (which mostly affects labor income as opposed to capital income) is not conceptually wedded to the notion of a basic income. Furthermore, this fact allows us to see that, perhaps, a capital tax would be preferable as a source of funding for basic income compared to income taxes.

There is a second reason why a uniform basic income is still not consistent with certain ideas of justice even if it were to be funded via income taxes. The reason is symbolic, but symbols hold a lot of sway in affecting our conceptions of desert and, consequently, of justice. When we implement a uniform basic income that will give money to individuals who are wealthy enough not to need it, we are telling those individuals who do need it to be really free that the needs of the well-todo are as pressing as theirs. But this is incorrect since people do vary in the degree that they need extra help to achieve real freedom. It will not do to say that those who are wealthy enough not to need it will be taxed more and be net losers. Why include them in the group of beneficiaries in the first place? The only feasible answer is that it would create more of a bureaucratic mess not to, and that it would stigmatize those receiving a basic income (as opposed to those who do not receive it).

To the first point, it is not clear that more bureaucracy will emerge. As I will argue below, we already have in place the basic categories that would enable differentiation in the dispensation of the basic income. In response to the second point, the stigmatization argument, it is also not clear that a differentiated basic income would create stigma on those receiving it, or on those receiving a larger income grant than others. For a start, many more people would receive a basic income than there are traditional welfare recipients today. When many more people are counting on some type of funding from the state, it is not far-fetched to

\footnotetext{
${ }_{19}$ The Alaska Permanent Fund is a state-owned investment fund established using oil revenues. It pays out an annual dividend to every man, woman, and child living in Alaska. In 2015, the dividend totalled \$2,072 per person.
} 
think that feelings of stigma stemming from receiving funds from the government will generally lessen among the population.

Additionally, the claim that receiving more of something that others do not need, or do not need as much, is invariably a source of stigma is not corroborated empirically. Defenders of a traditional basic income have argued that one virtue of the policy, compared to other forms of welfare assistance, is that it is not likely to cause high levels of stigma among recipients because everybody will get it regardless of economic need (see Van Parijs 1995, chap. 4). This is consistent with the argument that the more common a given program or policy is among the population at large, the less singled out those benefitting from it will feel. A gradated basic income still has this benefit. By and large, many people would get it, even if at different levels of funding. Differences in funding levels would not be immediately obvious to citizens, and the magnitude of those differences would not be easy to surmise in simple social interactions. But even if some of those differences became more apparent than others, that in itself is no reason to think that stigma would automatically ensue. Differences in government funding exist in many other spheres of society. If stigma was an automatic result of nonidentical government funding for all, people would feel stigmatized for getting more funding assistance from the government to buy a house than others or from receiving more tuition aid to attend university than others based on need; but there is no evidence that this causes stigma. Although I agree that stigmatization is a serious problem when it comes to some of the assistance programs intended for the most poor in society, I doubt that it is an equally serious problem when it comes to all types of governmental funding programs.

There is a third general objection against a gradated basic income. Disparity in initial disadvantage that we do not choose to bear and do not bring about upon ourselves by choice is an indicator of how our capacity to exercise moral agency varies. But it could be said that focusing on moral agency is too impractical since we cannot go about assessing every individual's moral responsibility for her life choices in order to implement a policy. However, it is in no way clear that the implementation of public policy calls for a case-by-case assessment of moral agency. As it is common in public policy implementation in general, the establishment of categories in which similar cases are grouped should be the norm. 
On which criteria should these categories be formed in the case at hand? Two natural indicators of moral agency-that is, the capacity to control one's life vis-à-vis circumstance-seem to be income and wealth. Income and wealth are not completely illustrative of our capacity for moral agency, but in a society where money and assets are linked to access to such precious goods as education, health, political influence, security, job prospects, and many more, it is reasonable to assume that the wealthier and income-rich will be in a better position to escape constraining circumstances than the poorer. The former will be able to exert control over the shape of their lives to a greater extent than the less fortunate members of society. Thus, income level and wealth may reasonably be measured to establish categories of entitlement when disbursing basic income in society. State bureaucracies are already familiar with these categories, which they use to determine tax liabilities and credits for all citizens eligible to pay taxes.

\section{AgENCY AND UNIVERSALITY OF THE GRANT}

We know that the constraints imposed by economic necessity might be more stringent for some individuals than for others. Imagine a situation where there is no basic income in effect, and wealth is only composed of earned income through work. A high earner who decides to opt out of work, and does not have the chance to become a high earner quickly or easily, is not in the same situation as a low earner who wants to opt out of work, since the latter will have to return to the labor force much sooner in order to survive. The higher earner is in a better position to afford not working. She can keep herself out of work for longer. In this sense, we could say that the higher earner is in a better initial position to exercise moral agency than the lower earner because she has access to valuable options the lower earner does not have, namely, the financial stability that income can buy. In consequence, having more valuable options - and more real freedom-gives the higher earner the capacity to claim a larger degree of moral responsibility for decisions she makes involving her opportunities. Following this logic, the idea that individuals who can afford to opt out of work independently, without incurring unacceptable costs, should not receive help from society seems reasonable. Society does not need to help them achieve control over their lives. They already have the capacity to do so by themselves. Retired millionaires-to revisit the Bill Gates example-would fall in this category. But if this is the case, it also follows that the generosity of the 
grant should track the recipient's capacity to live comfortably without relying heavily or solely on income derived from work. This capacity is not binary-society is not only composed of Bill Gates and regular folks who need a job and have no savings in the bank; there is a very broad spectrum in between. The reality is that people's circumstances vary according to their family background, place of residence, and personal luck, and it is fair to say that some individuals are in much better position than others to face the abundant obstacles that life throws their way. Some are fortunate enough to have their parents pay for college, while others need to obtain loans that will burden them for decades to come. Some may be able to obtain a promising first job due to good family connections, while others may have no such luck given the lack of social capital in their families. Some may be born in an area of great economic opportunity, while others may be born and raised in areas where unemployment is much higher than the national average. Circumstantial differences like these-which are just a few examplesextend throughout society. Even though we should not make the mistake of particularizing too much when thinking of justice, we should still be willing to make certain basic distinctions in the name of justice. Indicators of income and wealth, which already exist for taxing purposes, should be sufficient for this goal. ${ }^{20}$

This point motivates an important question for those who see a basic income policy as justified on a universal right to decent sustenance: What kind of a universal right is a right that is not enjoyed by all in an equal manner? The traditional argument for a basic income is based on the notion of a universal citizenship-right. This means that everybody who is a citizen should benefit from it; no other distinctions matter. But in order to answer the question we need to recognize that there are two different ways to conceive of the idea of universality as it concerns individual rights.

I propose to think of universal rights as belonging to two general categories. On one account of what a universal right is, the individual is protected by it without the requirement of having to qualify for protection. Examples of this instance include the universal right to life (in the sense of the right not to be killed), the right to humane treatment, and the right to choose whom to marry. Rights that are

\footnotetext{
${ }^{20}$ It may be the case that the elimination of economic inequality will not necessarily eliminate differences in status among individuals, but for the purposes of this discussion, I will limit my arguments to the sphere of economic inequality strictly. There are good reasons to think that starting there is already a worthy goal.
} 
automatically universal do not require from the individual any circumstantial status in the sense that all individuals are entitled to enjoy those rights irrespective of their particular situations. The only condition for their exercisability is mere existence as a human being.

On a second account of what a universal right is, the individual is passively protected by it qua human being, but the protection is activated only if some conditions are met. Examples of this instance include the right to be rescued, the right to political asylum, the right to vote, and the right to compensation for disability. The logic of the first account is that the bearer of the right does not have to be under any (special) circumstances to benefit from it. The logic of this second account makes this specialness a requirement. A right to be rescued requires that the individual be in a situation demanding rescuing (for instance, drowning). A right to political asylum requires that the individual be persecuted for her political or religious views. A right to vote requires that the person be over a certain age, and a citizen. A right to disability compensation demands that the beneficiary be disabled in some discernible way.

However platitudinous these observations may seem, they point to an important analytical concept, namely, automaticity in the exercise of rights. Some rights require a proof of need to be enjoyed however universal they are in their coverage. Other rights are more straightforward and apply automatically to all without requiring evidence that their protection needs to be activated. The concept of a universal right alludes to a prerogative that applies to everyone regardless of jurisdiction and other localizing factors, such as ethnicity, gender, race, age, nationality, and the like. In this sense, the second account of universality-non-automatic universality-fulfills this requirement. It still applies to everyone irrespective of morally arbitrary factors provided that their situation is of a certain special nature. Anybody, irrespective of race, ethnicity, gender, and so forth, can be disabled, in need of rescue, or in need of asylum.

I argue that the right to receive a basic income falls within the second account of universality, namely, non-automatic universality. Everybody is potentially a right-holder. But the right is not automatic because the individual must be in a certain situation to enjoy it. Existence as a person, or citizen, does not suffice as a criterion for being a beneficiary of the right. In this way, the argument defended in this paper deviates from traditional accounts of basic income, such as Van 
Parijs', that interpret uniform grants to be automatically applied to all. The citizenship-based justification for the basic income policy rightfully ignores differences that are morally irrelevant to justice such as gender and race, but it also overlooks other differences that should be taken into consideration, such as income and wealth. As argued above, these considerations reflect the degree of moral agency that the individual can exercise when making important life choices. Our moral agency, in turn, reflects the magnitude of real freedom that we enjoy prior to receiving the grant. As such, moral agency indicates the degree of constraint by social circumstances; these are, presumably, constraints that an individual has not chosen.

The right to receive a basic income is based on the principle of universal citizenship, but activation of the right is not automatic upon being a citizen or resident merely. One needs to be a citizen or resident with no independent wealth or with wealth below a (socially) determined level. Basic income theorists' reluctance to interpret the value of grants according to social advantage rests on a view of human agency whereby the individual is rightly said to be able to control what she desires. Thus, because a person can control what she desires, we do not think that society has the duty to cater to her expensive tastes in the name of justice; it is believed that the individual could decide to dispense with an expensive taste or not act upon it. But this interpretation of agency disregards other aspects of human life besides preference that should also be subject to some responsibility-based analysis. If we should hold individuals responsible for something they can control-such as an expensive taste-by the same token, we should not hold them overtly responsible for what they cannot control, such as initial disadvantage in life. Expensive preferences do not deserve the attention of justice; but other variables that differentiate individuals from each other do have a strong claim to being taken seriously from the standpoint of justice. These are socio-economic disparities that spring from unchosen life circumstances that have the power to shape prospects and opportunities in significant ways. Unlike expensive tastes that are under an individual's control, non-chosen social disadvantage cannot be controlled or (easily) modified. Additionally, non-chosen disadvantage can have pervasive consequences in most spheres of life, not just in one particular area, as could be the case with an expensive taste such as the preference for a luxurious means of transportation. 


\section{POLICY IMPLICATIONS}

The policy upshot of my arguments in this article is a gradated basic income grant. The idea of differentiated rates in the provision of the grant is not unheard of in the economic literature dealing with basic income. ${ }^{21}$ Rather, it is this aspect of a basic income policy that reflects liberal-egalitarian intuitions better than an identical, uniform provision..$^{22}$ The idea that unfortunate social circumstance should not be overtly determinant of the individual's fate is a cornerstone of liberal egalitarianism. As I explained in sections One and Two, our capacity to control our own life trajectory is strongly constrained by the force that social contingencies exert on us. Thus, differentiated basic income schemes are fit to address morally arbitrary factors which constrain people's real freedom to make choices in life.

One may then ask: is this interpretation of basic income informed by a luck-egalitarian logic? Luck egalitarianism is a view about social and distributive justice that emphasizes the principle that individuals should not be worse off due to circumstances that are beyond their control, that is, for circumstances for which they are not morally responsible (Zimmerman 1987). In the same vein, luck egalitarianism maintains that it would be unjust to pay attention to (and compensate for) differences that negatively affect the individual but for which he can claim responsibility and be properly blamed (see Dworkin 1981b).

The approach to moral agency defended above seems to be connected to the luck-egalitarian philosophy because it argues that people should be held responsible for the advantages they enjoy and not given unnecessary assistance. However, I make no attempt to argue that people should be denied help if they suddenly encounter trouble or distress due to their own fault. This issue goes beyond the scope of this

\footnotetext{
${ }^{21}$ See Callan et al. (1999). Here, the author investigates the implications of introducing different types of basic income schemes. He considers the possibility of a basic income with a differentiated rate for adults, setting the latter at the already existing agerelated rates for single people used in social assistance programs. Additions for lone parents and dependents are modeled too. For further treatment of gradated basic income, see Zelleke (2005). In that article, the author considers a number of variable basic income models that differ in their rates, according to age and family size.

${ }^{22}$ The reader may be left wondering, why not a negative income tax? There are several reasons why a gradated basic income would be preferable. First, the individual would not have to wait until the end of the year to get the benefit (as she would with a NIT). Secondly, the gradated basic income would in principle apply to everyone regardless of job-holding status. The NIT, by contrast, benefits people earning below a stipulated income threshold. In other words, it applies to participants in the wage economy only.
} 
paper. ${ }^{23}$ My analysis is limited to claiming that, because some individuals already enjoy a relatively high level of real freedom before the basic income is implemented, it would be a waste of resources and morally unjustified to include them as natural beneficiaries of the policy. Hence, this is not an endorsement of luck egalitarianism; it is, rather, an attempt to alleviate the effect of morally arbitrary disadvantages such as initial low economic status. In this sense, the argument defended in this paper is more Rawlsian than it is luck-egalitarian.

Moreover, I should clarify that wealthier individuals should have the opportunity to demonstrate to the state that their real freedom situation may have changed, and that a basic income would now be needed and justified in their case. Having more real freedom to start with than others does not mean that we will always be in that situation. Thus, I am not a luck egalitarian in an important respect: I am not willing to defend the idea that the reasons for exiting the group of advantaged members of society must be assessed through the lens of moral responsibility. Everybody who currently lacks the freedom to justify a basic income should be entitled to get one. ${ }^{24}$

One may wonder whether the traditional drawbacks of means-tested welfare policy will not persist with a gradated grant. Individuals would still have to provide sufficient information about their personal situations, some of which may be stigmatizing or embarrassing to reveal. This is an important consideration to keep in mind when implementing public policy. Equality and justice are not the only goods the latter may aim at achieving. Self-respect is another. One important argument in favor of a uniform basic income is that it will do away with stigmatizing social security. How then is this concern addressed by a gradated grant?

First of all, I do not believe that presenting proof of social disadvantage in order to assess which level of funding one is entitled to has the same stigmatizing effects as other social programs may have. Under an ideal scheme, a lot of people receive a grant (unless they are

\footnotetext{
${ }^{23}$ See Zimmerman (1987) for a glimpse of this debate.

${ }^{24}$ An obvious objection here is what Richard Arneson (1997) has called the undeserving poor objection. Suppose someone continuously wastes resources and becomes poor again. Should we really keep on providing this person with an income grant? This is a difficult question that necessitates more space than I can provide in this paper. However, it will suffice to say that it is not inconsistent with my position to argue that the gradated basic income does not have to be provided eternally to the undeserving in this respect, provided other forms of humanitarian welfare exist that will prevent death for the chronically irresponsible.
} 
wealthy) no matter how differentiated. Today, not everybody is the beneficiary of welfare assistance. The gradated basic income will be means-tested indirectly insofar as it will apply differently to people in accordance with their levels of socio-economic advantage, and provided that such disadvantage is not the result of repeated acts of irresponsible (and avoidable) behavior. But it needs stronger justification to say that everybody thinks that it is humiliating to have a low income, or little wealth, in the way that some people think it is humiliating to receive means-tested assistance. The difference may be purely psychological, but it is psychology that explains feelings in reaction to stigmatization (see Goodin 1998). On the other hand, a sense of humiliation among recipients of welfare benefits is likely to be rooted in the widespread belief that the assistance is not a question of human rights but of charity. When a benefit is attributed to the charitable giving of a third party, the structural injustice that explains, in great part, why the individual is in a disadvantaged position and in need of the benefit is typically ignored and considerations of individual merit take priority. A gradated basic income would eliminate this problem because everyone, or a great majority, would receive a version of it. Critics are surely right to point to the bureaucratic difficulties of securing differentiated social provision. But my suggestion, even though more bureaucracy-prone than a uniform basic income, would still be simpler than means-tested social welfare, for which monitoring plays a big part. In any case, it is surely important to highlight that an overriding aim of social policy should be to avoid excessive intrusion into citizens' privacy.

A gradated basic income can realize many (if not all) of the benefits of a uniform basic income. One can easily see how the receipt of income regardless of employment status will constitute a great help for the most vulnerable at the expense of the not so vulnerable, who will pay progressively higher taxes to fund the policy. Van Parijs offers another reason why his basic income proposal is a desirable redistributive instrument. He argues that the basic income serves as means to achieve job-rent sharing in society (Van Parijs 1995, chap. 4). Job-rents are the surplus in wages that result from the labor market not clearing. In simple words, employers pay employees salaries above the marketclearing equilibrium because they want to retain workers and save themselves the cost of training and administration that would result from a quicker rotation of jobs (characteristic of a pure capitalistic equilibrium in the supply and demand of labor). Van Parijs (1995, chap. 
4) explains that this surplus, or rent, prevents people outside the job market from entering it and keeps others in at the expense of those who cannot enter. The basic income makes employees share the rents that their jobs produce via taxation. The gradated basic income realizes this distributive benefit even more efficiently than the uniform grant. This is so because those individuals who earn more are going to receive less in comparison with those who earn less. Thus, under a gradated basic income, the sharing would be fairer in that it would burden more proportionally those individuals with higher earnings. ${ }^{25} \mathrm{~A}$ scheme that is sensitive to differentials in advantage, primarily measured on the basis of income and wealth takes away more from the rents of the better employed (i.e., those with high-paying jobs).

The basic income policy also constitutes a positive externality for a market capitalist economy. The benefit of a basic income, it is claimed, is that it helps stabilize aggregate demand, which in turn fuels production and investment (Constantin 2002). ${ }^{26}$ Albeit complex, the rudimentary idea is that by redistributing income in the form of a grant, the consuming market becomes larger, which in turn signifies higher rates of investment-return in the medium-to-long runs. Coupling the policy with an active pro-investment outlook on the part of the government may make the capitalistic scenario even more appealing to capitalists and investors. One could surmise that the cost of labor will be higher under a basic income scheme because employers will have to offer more attractive wages in order to attract workers who no longer fear starvation if they do not manage to get employed. But this is not necessarily an obstacle. For example, in no highly unionized society has the fact of relatively expensive labor gotten in the way of economic development, the Scandinavian model being a paradigmatic example (Madsen 2006; Pekkarinen, Pohjola, and Rowthorn, 1992). That said, however, a gradated basic income may also allow for more flexible labor market rules of hiring and firing in certain sectors because society can rely on the grant as a safety net that will make unemployment more bearable. Flexible labor markets would be good for investment,

\footnotetext{
${ }^{25}$ The wealthy who do not work do not participate in job-rent sharing. However, the fact that they do not work makes the distributive consequences of a gradated basic income even more welcome. One could say that it is problematic from the point of view of equality that some have to work for a living and others do not without this difference having any effect on who receives help from society.

${ }^{26}$ For a fuller discussion on the effects of basic income and other similar policy instruments, see Wright (2003), Przeworski (1986), and Bradbury, Ephraim, and McNair (2002).
} 
obviously. The reason why is that potential employers would not have to worry about high labor costs since much of the individual's income would be given by the basic income.

By definition, a gradated basic income is better suited to addressing redistributive concerns than a uniform basic income. A gradated scheme would achieve redistribution in a much more efficient way than a uniform grant. If those who have less receive proportionally more than those who have more, the redistributive effects of the policy are enhanced.

A differentiated basic income would be better for achieving longterm growth as well. If the argument that aggregate demand being increased on account of a better distribution of income has any purchase, it is clear that a policy that deepens redistribution by helping those who need help more, will also create more opportune conditions for production and investment. Thus, both because it is a more effective and fairer redistributive tool, and because it does not hamper economic growth, a gradated basic income is no less preferable than a uniform basic income.

\section{CONCLUSION}

This article challenged the idea that a uniform basic income is consistent with (and required by) justice. I have argued that we should attend to disparities in access to socio-economic advantage and that attention to those differences does not detract from the universality of the proposal. This universality will still obtain, but it needs to be activated when certain conditions of need are met. A focus on moral agency, understood as the capacity of an individual to control their own fate, as opposed to being compelled by the force of social circumstance, constitutes the main philosophical building block in the rejection of distributive uniformity. This thinking goes together with the basic intuition that identical treatment is not always conducive to giving everyone's interests equal consideration.

For defenders of the traditional basic income, uniformity protects us against an emphasis on welfare considerations, which justice should ignore. According to the consensus view, if the grant is the same for all, then we avoid subsidizing expensive tastes that some individuals may need to lead a minimally good life. I argued that this position, however intuitive, overlooks other differences that need to be considered for the sake of justice. Such considerations include differences in access to 
advantage and primary social goods. At one extreme, when demanding uniform treatment, those able to enjoy considerably high levels of real freedom without the help of society detract from the real freedom of others not so fortunate themselves.

\section{REFERENCES}

Ackerman, Bruce, and Anne Alstott. 2004. "Why Stakeholding?" Politics and Society 32 (1): 41-60.

Arneson, Richard J. 1997. "Egalitarianism and the Undeserving Poor." The Journal of Political Philosophy 5 (4): 327-350.

Atkinson, Anthony B. 1996. "The Case for a Participation Income." The Political Quarterly 67 (1): 67-70.

Bradbury, Farel, Owen Ephraim, and Lord Duncan McNair. 2002. "Basic Income and the Advanced Economy." Basic Income European Network, $9^{\text {th }}$ International Congress. https://basicincome.org/bien/pdf/2002Bradbury .pdf>.

Callan, Tim, Cathal O'Donoghue, Holly Sutherland, and Moira Wilson. 1999. "Comparative Analysis of Basic Income Proposals: UK and Ireland." The Microsimulation Unit Research Notes MU/RN/31. https://www.iser.essex.ac.uk/files/msu/publications/pdf/rn31.pdf>.

Campbell, Joseph K. 2008. "New Essays on the Metaphysics of Moral Responsibility." The Journal of Ethics 12 (3/4): 193-201.

Casal, Paula. 2007. "Why Sufficiency is Not Enough.” Ethics 117 (2): 296-326.

Constantin, Paulo D. 2002. "The Positive Externality of Basic Income in a Capitalist Economy." Basic Income European Network, $9^{\text {th }}$ International Congress. $<$ https://basicincome.org/bien/pdf/2002Constantin.pdf >.

Dworkin, Ronald. 1981a. "What is Equality? Part 1: Equality of Welfare." Philosophy \& Public Affairs 10 (3): 185-246.

Dworkin, Ronald. 1981b. "What is Equality? Part 2: Equality of Resources." Philosophy \& Public Affairs 10 (4): 283-345.

Elster, Jon. 1986. "Comment on Van der Veen and Van Parijs." Theory and Society 15 (5): 709-721.

Fischer, John M. 1999. "Recent Work on Moral Responsibility.” Ethics 110 (1): 93-139.

Fischer, John M. 2008. "Responsibility and the Kinds of Freedom." The Journal of Ethics 12 (3/4): 203-228.

Frankfurt, Harry G. 1969. "Alternate Possibilities and Moral Responsibility." The Journal of Philosophy 66 (23): 829-839.

Friedman, Milton. 1962. Capitalism and Freedom. Chicago, IL: University of Chicago Press.

Goodin, Robert. 1998. "More Than Anyone Bargained For: Beyond the Welfare Contract." Ethics \& International Affairs 12 (1): 141-158.

Lerner, Melvin. 1980. The Belief in a Just World: A Fundamental Delusion. New York, NY: Plenum Press.

Levy, Neil, and Michael McKenna. 2009. "Recent Work on Free Will and Moral Responsibility." Philosophy Compass 4 (1): 96-133.

Madsen, Per K. 2006. "How Can It Possibly Fly? The Paradox of a Dynamic Labour Market in a Scandinavian Welfare State." In National Identity and the Varieties of 
Capitalism: The Danish Experience, edited by John L. Campbell, John A. Hall, and Ove K. Pedersen, 323-355. Montreal: McGill University Press.

Nagel, Thomas. 1991. Equality and Partiality. Oxford: Oxford University Press.

Paine, Thomas. 1791. "Rights of Man." In The Writings of Thomas Paine, Volume II, produced by Norman M. Wolcott, and David Widger. Project Gutenberg, last updated November 15, 2012. http://www.gutenberg.org/files/3742/3742-h/3742h.htm.

Parfit, Derek. 1991. "Equality or Priority?" The Lindley Lecture, The University of Kansas.

Pekkarinen, Jukka, Matti Pohjola, and Bob Rowthorn, eds. 1992. Social Corporatism: A Superior Economic System? Oxford: Clarendon Press.

Przeworski, Adam. 1986. "The Feasibility of Universal Grants under Democratic Capitalism." Theory and Society 15 (5): 695-707.

Rawls, John. 1971. A Theory of Justice. Cambridge, MA: The Belknap Press of Harvard University Press.

Surowiecki, James. 2016. “The Case for Free Money: Why Don't We Have Universal Basic Income?” New Yorker, June 20, 2016.

Valente, Marcela. 2009. "LATIN AMERICA: Movement for Basic Income for All." Inter Press Service, March 18, 2009. http://www.ipsnews.net/2009/03/latin-americamovement-for-basic-income-for-all/>.

Van Parijs, Philippe. 1991. "Why Surfers Should be Fed: The Liberal Case for an Unconditional Income.” Philosophy \& Public Affairs 20 (2): 101-131.

Van Parijs, Philippe. 1995. Real Freedom for All: What (if Anything) can Justify Capitalism? Oxford: Oxford University Press.

Van Parijs, Philippe, and Yannick Vanderborght. 2017. Basic Income: A Radical Proposal for a Free Society and a Sane Economy. Cambridge: Harvard University Press.

White, Stuart. 1997. "Liberal Equality, Exploitation, and The Case for an Unconditional Basic Income.” Political Studies 45 (2): 312-326.

Widerquist, Karl. 2006. "Who Exploits Who?" Political Studies 54 (3): 444-464.

Wright, Erik O., ed. 2006. Redesigning Distribution: Basic Income and Stakeholder Grants as Alternative Cornerstones for a More Egalitarian Capitalism. New York, NY: WW Norton and Co.

Wright, Erik O. 2010. Envisioning Real Utopias. London: Verso.

Zelleke, Almaz. 2005. "Basic Income in the United States: Redefining Citizenship in the Liberal State." Review of Social Economy 63 (4): 633-648.

Zimmerman, Michael J. 1987. "Luck and Moral Responsibility." Ethics 97 (2): 374-386.

Julia Maskivker is Associate Professor of Political Science at Rollins College in Winter Park, Florida. Her research is on philosophical theories of justice and equality as well as on democratic theory.

Contact e-mail: <jmaskivker@rollins.edu> 